\title{
Lithological Mapping from OLI and ASTER Multispectral Data Using Matched Filtering and Spectral Analogues Techniques in the Pasab-e-Bala Area, Central Iran
}

\author{
Zahra Hadi Vincheh*, Ramin Arfania \\ Department of Geology, Isfahan (Khorasgan) Branch, Islamic Azad University, Isfahan, Iran \\ Email: ${ }^{*}$ zahrahadi2010@gmail.com, rarfania@khuisf.ac.ir
}

How to cite this paper: Vincheh, Z.H. and Arfania, R. (2017) Lithological Mapping from OLI and ASTER Multispectral Data Using Matched Filtering and Spectral Analogues Techniques in the Pasab-e-Bala Area, Central Iran. Open Journal of Geology, 7, 1494-1508.

https://doi.org/10.4236/ojg.2017.710100

Received: August 30, 2017

Accepted: October 17, 2017

Published: October 20, 2017

Copyright $\odot 2017$ by authors and Scientific Research Publishing Inc. This work is licensed under the Creative Commons Attribution International License (CC BY 4.0).

http://creativecommons.org/licenses/by/4.0/

c) (i) Open Access

\begin{abstract}
Using satellite data for geological mapping beside saving time and reducing coast leads to increased accuracy. In this study, the result of remote sensing techniques has been compared for manifesting geological units. The study area is limited to 1:25,000 rectangle of Pasab-e-Bala which is located in the northeast of Isfahan and West of Qom-Zefreh fault. This region mainly consists of Devonian and Quaternary sedimentary units. In this study, ASTER and OLI satellite data has been corrected atmospherically and radiometrically. Spectral Analogues method and OLI band combination (652) in RGB image were powerful in distinguishing various rock units. Finally, a new geologic map of the Pasab-e-Bala area was created by integrating the results of remote sensing, previous geological maps and field inspection. It is concluded that the workflow of Landsat 8 image processing, interpretation and ground inspection have a great potential to identify geological formations. According to field data originality, accuracy of the produced map was evaluated through calculating kappa index and overall accuracy and a thematic accuracy of $86 \%$ was achieved for geological formations.
\end{abstract}

\section{Keywords}

Geological Mapping, ASTER, OLI, MF, Spectral Analogues, Kapa Index, Thematic Accuracy

\section{Introduction}

The study area is located in $58 \mathrm{~km}$ northeast of Isfahan in Central Iran (Figure 1 (a)). Due to proximity to the desert, the climate of this area is warm tempera- 
ture and dry in summer and cold temperature and dry in winter. The most important natural phenomena in the study area are hot spring systems, which have a significant impact on regional mineralization and creation of travertine and bentonite mines. Mainly the area consists of Devonian to Quaternary sedimentary units. Remote sensing instruments can provide detailed information on the mineralogy and geochemistry of the rock types comprising the Earth's surface, and have been used for decades to map rocks, mineral assemblages and weathering characteristics [1]-[6].

The type of land cover or mineral composition of the surface of the earth is determined using multispectral data based on the spectral effects. The Landsat and Terra satellites are of the most successful earth's surface observation systems. Regarding huge advancements in sensors technology, the spectral and spatial resolution of remote sensing data has been improved. The VNIR spectral range is used by nearly all the broadband reflective multispectral sensor systems. The SWIR spectral range is regarded as the most effective for lithological and mineral mapping because most rock types have the most reflectance in the 1.55 $1.75 \mu \mathrm{m}$ range (Figure 2) and hydrous (clay) minerals (often products of hydrothermal alteration) have diagnostic absorption features in the spectral range 2 - $2.4 \mu \mathrm{m}$ [7]. The advanced spaceborne thermal emission and reflection radiometer (ASTER), launched on board NASA's Terra spacecraft in December 1999, were developed based on the success of airborne Thermal Infrared Multispectral Scanner (TIMS). ASTER consists of three separate subsystems with a total of 14 spectral bands across the VNIR, SWIR and TIR with three, six and five bands in each part of the spectrum respectively [8]. Several recent studies have focused on lithological mapping using ASTER data including all VNIR, SWIR and TIR wavelength regions [9] [10] [11] [12] [13]. ASTER sensor has a
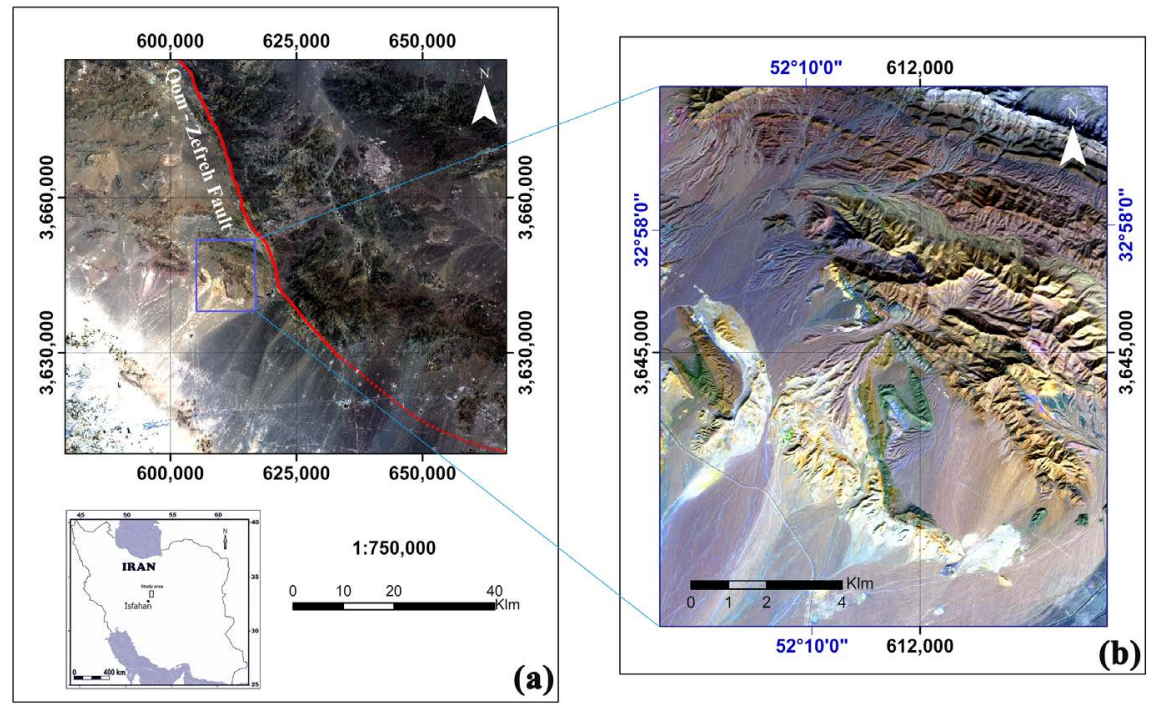

Figure 1. (a) Satellite image (Landsat 8) of the study area; (b) The band combination RGB: 652 from the study area. 
good combination of spatial resolution in the VNIR, SWIR bands and multispectral thermal data bands which are very useful in geological applications (Figure 2).

The VNIR bands with a resolution of $15 \mathrm{~m}$ are adequate for distinguishing broad categories of land surface such as vegetation, water, soils, urban areas, superficial deposits and general rock outcrops while the six narrow SWIR bands of $30 \mathrm{~m}$ resolution have the potential to map major mineral assemblages (rock forming and alteration) and lithological unites [7]. Landsat 8 is the latest satellite in this series of Landsat satellites picking up images using two sensors. The first sensor is the operational land image (OLI), that takes the image from 9 short wavelength bands with a resolution of 30 meters for the VNIR and SWIR bands and the second sensor is a thermal infrared sensor (TIRS) that takes the image from two bands of thermal wavelength and includes a panchromatic band with a resolution of 15 meters [15]. In this study, we used the $1 \mathrm{~T}$ Level of OLI sensor data with it's the panchromatic band and also VNIR, SWIR bands of 1B level of ASTER sensor data. Geological maps on the scale of 1:25,000 are the most important tools for presenting geological surveying results and regionally display geological unit, especially their distribution, composition, structural relation and age. Collecting the existing geological data, preparing topographical maps for field surveys, providing necessary equipments for field work, informing the authorities, gathering samples and recording of field observations are required to prepare geological maps in field method. In field works, expenses such as cost of travel, vehicle, equipment and assistance are the most costly part of the program and providing and supplying of the items mentioned above is necessary for any of these field acquisitions to control the costs of the mapping project [16]. This research aimed to use satellite data in the preparation of geological map, which will lead to saving time and reducing coast, as well as increasing the accuracy of mapping operations. So, in this method, access to geological maps is more cost effective.

\section{The Geological Setting}

The study area is tectonically considered as sedimentary part of the Sanandaj-

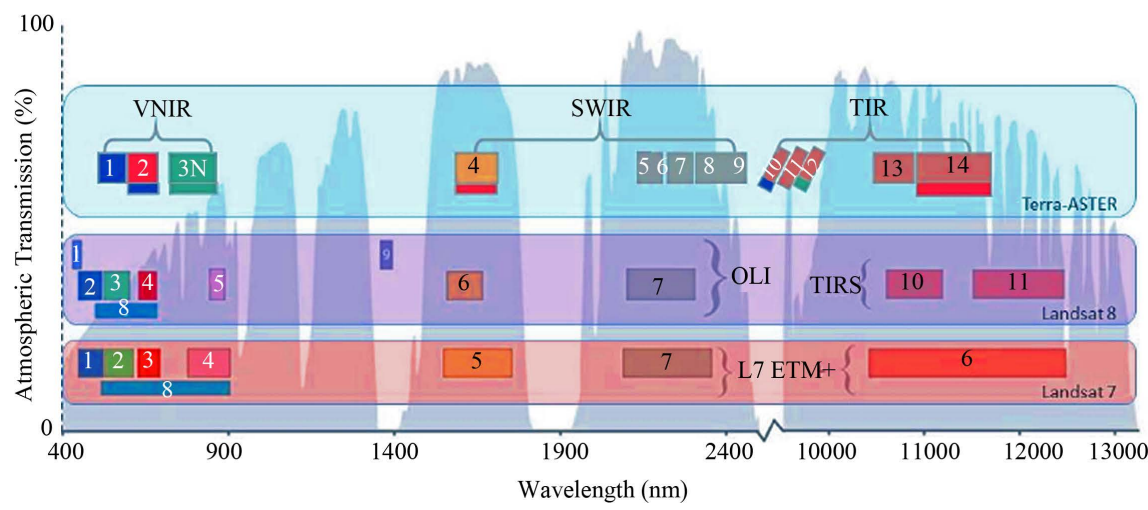

Figure 2. The spectral range comparison for Landsat $8(\mathrm{OLI})$, Landsat $7(\mathrm{ETM}+)$ and ASTER, this band distribution as shown in the USGS documents [14]. 
Sirjan Zone. The Sanandaj-Sirjan Zone is located between the Urumieh-Dokhtar Magmatic belt and the Zagros Fold-Thrust Belt [17]. The Urumieh-Dokhtar Magmatic belt is composed of a series of massive volcanic and pyroclastic rocks associated with it that extends from Sahand to Bazman and have seen wide activities in Cenozoic. In the Eocene, the most intense volcanic activities have occurred in this zone so that pyroclastic rocks in the south in form of Urumieh-Dokhtar belt and parallel to Sanandaj-Sirjan belt have been developed and andesite and dacite rocks have covered a vast part of the area [18]. The Qom-Zefreh fault with the approximate NW-SE trend divided the Sanandaj-Sirjan Zone and The Urumieh-Dokhtar Magmatic belt. The eastern part of the fault Qom-Zefreh includes intrusive and volcanic rocks and its Western part includes high fractured sedimentary units that our study area is located in this section Figure 1(a). In economic terms, hot springs have formed the travertines of the region and these mines are currently active. In terms of stratigraphy, the most important rocks and sediments covering the area can be classified according to the age and the time of the appearance in the following order from old to new accordingly Figure 3.

The oldest rock units (Paleozoic period) of the study area are the Bahram and Jamal formations, which consists of fossiliferous limestone, dolomite and shale.

The Sorkh shale, Shotory and Naiband formations are formed in the Mesozoic period, which contains red ferruginous quartzite, shale, dolomite and grey limestone.

In the Jurassic and Triassic periods, sedimentary units such as shale, sandstone, red conglomerate, and limestone are formed in the region. The lower red formations (upper and lower members) and Qom formation are the most important formations in the Cenozoic period, which consists of conglomerate, red sandstone and yellow fossiliferous limestone. In the Quaternary period, the most important lithology in this area is travertine from hot springs [19].

\section{Methods}

\subsection{Data Preprocessing}

In this study VNIR and SWIR bands OLI data and the panchromatic band taken

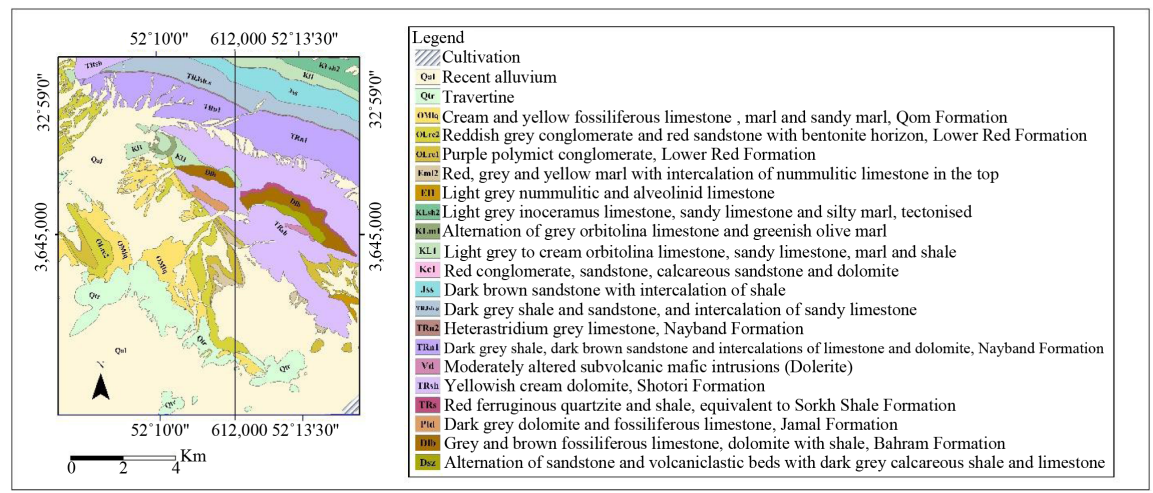

Figure 3. Geological map of the study area [19]. 
in 2015 and VNIR and SWIR bands (LIB) ASTER data taken in 2002 were used. Digital image preprocessing is a set of techniques that provide using more precision and less noise data. First, both data has been corrected atmospherically and radiometrically, The Fast Line-of-sight Atmospheric Analysis of Spectral Hypercubes (FLAASH) model was applied to the VNIR, SWIR dataset to correct the atmospheric influence and convert radiance data to reflectance images [20]. The negative effects of atmosphere and topography on the data were removed and finally the data with less noise were processed.

\subsection{Data Processing}

Color image is made by three different bands combination and assigning a color of the three primary colors, red, green, and blue to each band. Since most satellite images are available in multi-band formats, the study of a band does not provide much information. By combining multiple bands, we can investigate details of the features better than before. Awareness of the interactions between different wavelengths is important for identifying the features and different types of land cover. In making false color combinations it is better to use bands with less correlation [21]. In this research, the False Color Composite (FCC) with RGB: 652 [22] was used to visualize the formations. This combination highlighted the geological features of the region with greater clarity and resolution.

Minimum Noise Fraction (MNF) is a modified linear algorithm [23], which determines the inherent dimensions of image data. This method is used to separate data from noise and reduces the dimensions of data information; it helps reducing the spectral and noise dependence of image bands and the amount of error existing in detection of the target features [24]. MNF is a useful algorithm which applies two cascaded principal components analyses for reducing the dimensionality of multispectral data and minimizing the noise in the imagery. The two-step transformation could separate the noise from useful information [23], [25]. So in this conversion, a graph of eigenvalue representing the values for each band is obtained. The MNF algorithm divides the data in two categories: The first part is the data with eigenvalues above 1, which includes useful and without noise information and the second part is the data with eigenvalues of less than or equal to 1 that includes noises [24]. MNF eigenimages could be directly used for vegetation and lithological mapping [26]. In this study, the VNIR and SWIR data were used for MNF transformation.

The Matched Filtering (MF) is the optimal linear filter for maximizing the signal-to-noise ratio (SNR) that was originally known as a North filter. MF relies on correlating the received signal (a vector) with a filter (another vector) that maximizes the enhanced signal parallel to the signal [27]. The results of MF appear as a series of grey scale images for each selected endmember. Floating-point provides a mean of estimating the relative degree of match to the reference spectrum and approximate sub-pixel abundance, where 1.0 is a perfect match. In histogram the background material's data is centered on 0 and the target (end- 
member) appears in the upper tail of the histogram [28]. In this research, the trains were provided by Region of Interest (ROI) method and ASTER data. The images obtained from the MF method signified the prospective lithology units much better than the Mixture Tuned Matched Filtering (MTMF) method.

The Spectral Analogues tool maps the occurrence throughout an image of some desired material. Spectral Analogues uses spectral matching algorithms that compare the spectrum of each pixel to the mean spectrum of user-specified training pixels. You must know at least one location in the image where the desired material exists, usually through visual observation or prior knowledge, so that it can be used for training. The Spectral Analogues tool is designed for use with multispectral data [24]. After applying this method, we have three types of outputs: MF, SAM, and MF/SAM. The MF/SAM output Suppresses false positives that may be present in one method, but not the other, while enhancing true positives. For example, a pixel containing water has a high MF value and low SAM value. A high value divided by a low value results in a very large value, therefore enhancing the positive result [24]. In this research, the Trains were provided with OLI data, and according to the results of three types of outputs, in most cases, the MF/SAM ratio is very good for lithological detection Figure 4.

\section{Discussion}

\subsection{Matched Filtering (MF) Method}

MF is used to find the abundances of user-defined endmembers using a partial unmixing. This technique maximizes the response of the known endmember and suppresses the response of the composite unknown background, thus matching the known signature. It provides a rapid means of detecting specific materials based on matches to library or image endmember spectra [28]. In this research, the selected trains were provided by ROI method and ASTER data. These selected trains were applied in the MF method. Outputs include gray scale images which the target pixels are bright pixels Figure 5 and Table 1.

\subsection{Spectral Analogues Method}

Spectral Analogues uses spectral matching algorithms that compare the spectrum of each pixel to the mean spectrum of user-specified training pixels [24]. In this research, the selected trains were provided using ROI method and OLI data, these selected trains were exerted in the Spectral Analogues method. The outputs consisted of three types of data, SAM, MF, and MF/SAM. In the MF, MF/SAM outputs, the images are Gray Scale that the target pixels are the bright ones. In SAM output the target pixels are dark. Best image for drawing each lithology was determined by comparing the three images Figure 6 and Table 2 .

\section{Results}

Geological formations were determined by examining the images obtained from 


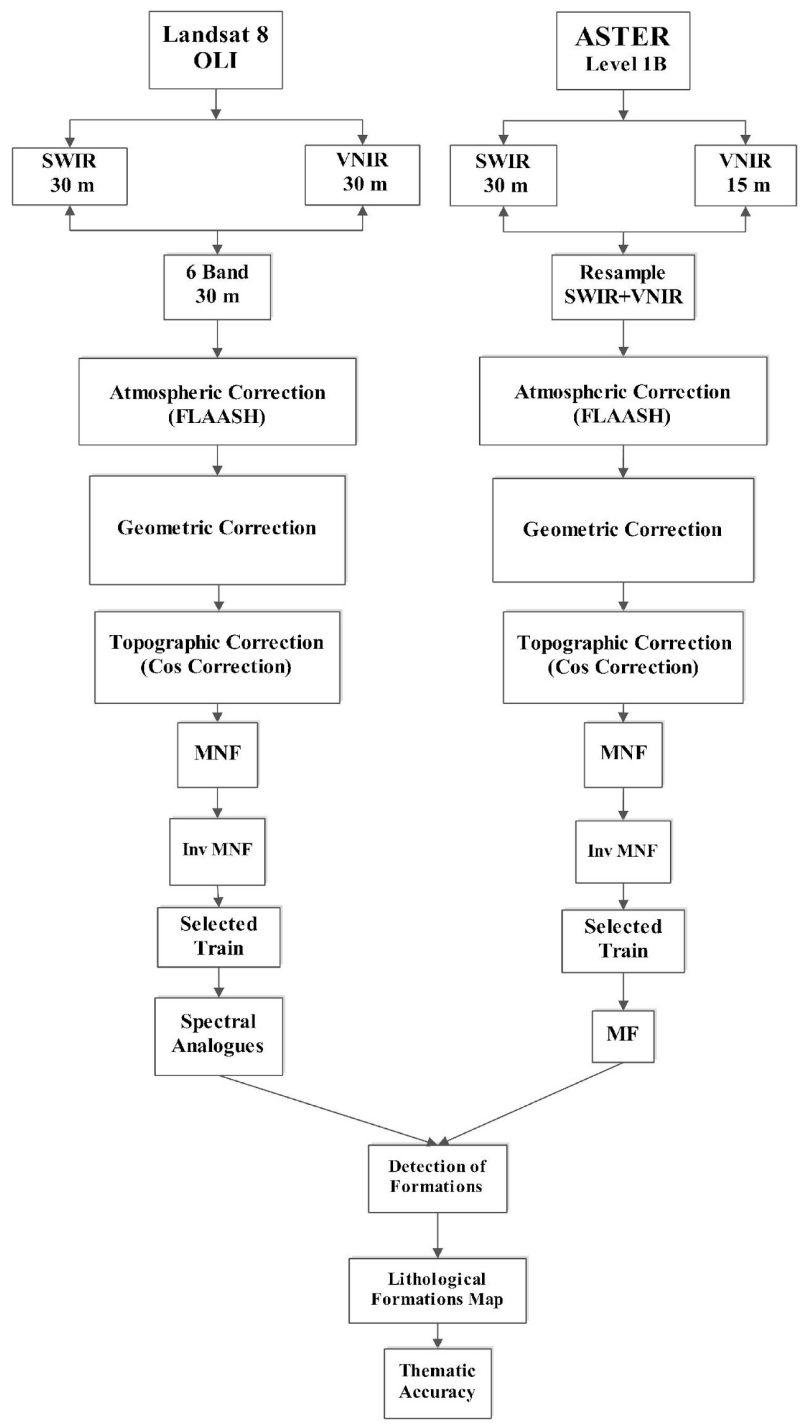

Figure 4. The flowchart of ASTER and OLI data processing steps.

the Matched Filtering and Spectral Analogues methods and also, the exact boundary of each formation was drawn through comparing these images to the image obtained from the FCC with RGB (652) (Figure 1(b)).

\section{Assessing the Accuracy of the Classification Map}

Maps help us to measure the location and distribution of the resources, to analyze their interactions, to find suitable locations for specific actions and plan for future events. To obtain better results for the map data, the determination of their accuracy is mandatory.

For accuracy assessment of the formation's map, the thematic accuracy method was done. The thematic accuracy deals with labels or descriptive properties of the map's features and modules the difference between phenomena's label and names on map and their actual nature on Earth.

The thematic accuracy done in two ways: 


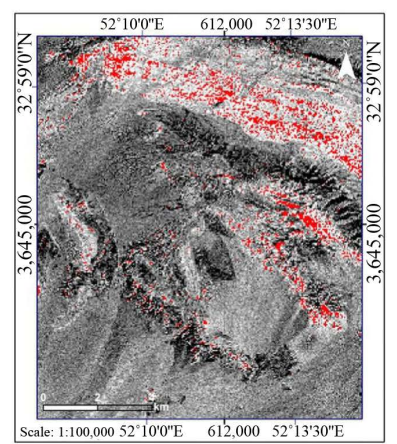

(a)

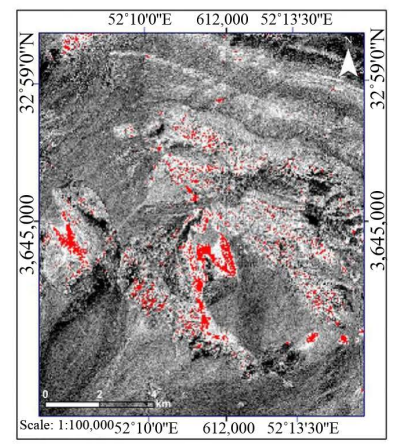

(e)

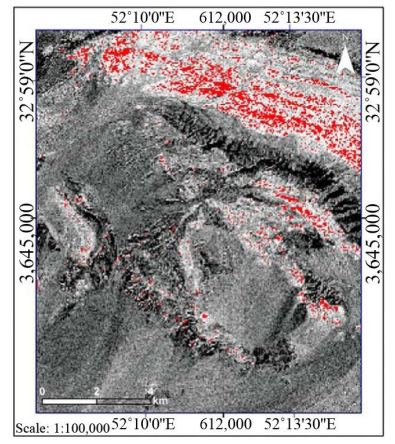

(i)

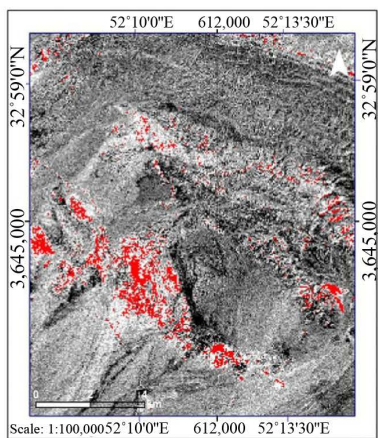

(b)

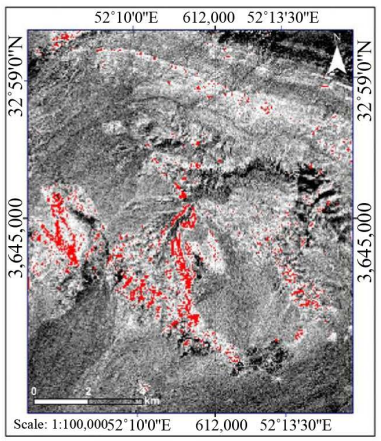

(f)

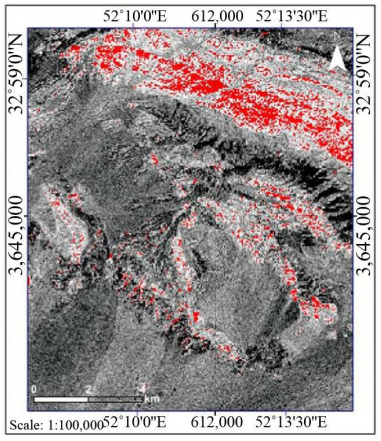

(j)

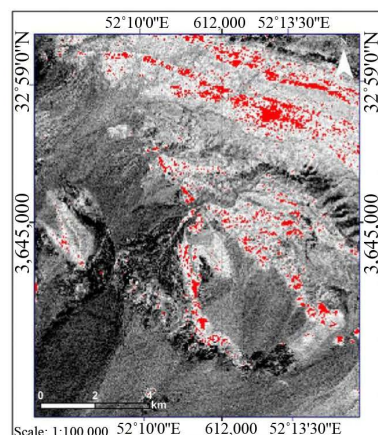

(c)

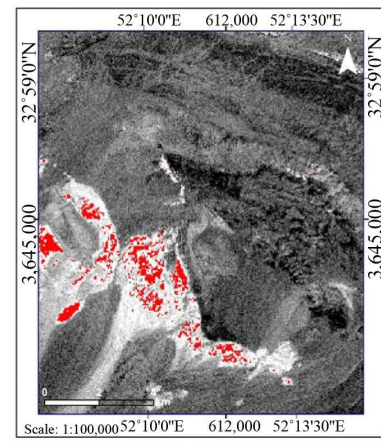

(g)

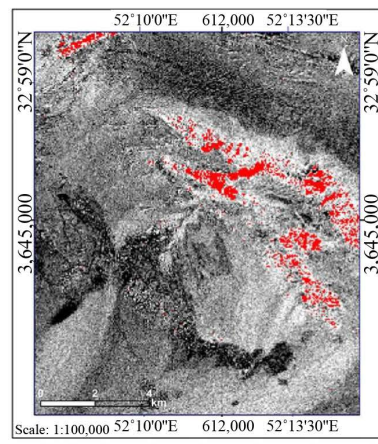

(k)

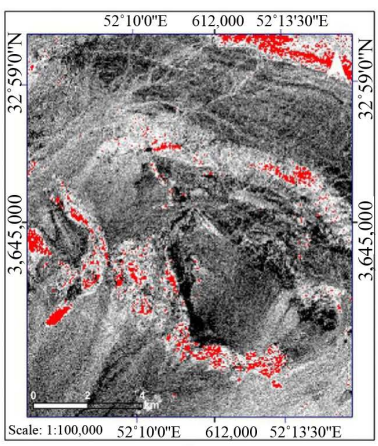

(d)

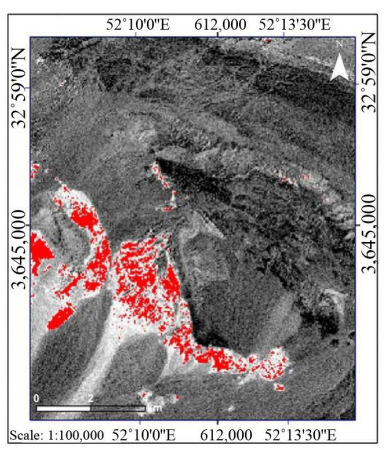

(h)

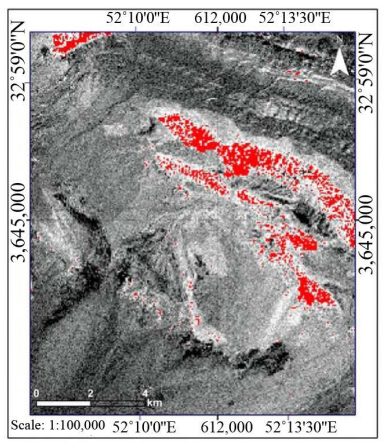

(1)

Figure 5. The images from MF method in ASTER data.

Non-Site-Specific Accuracy evaluation and the Site-Specific Accuracy evaluation which in former, only the total area of classes is calculated and their location is not considered. However, in the Sites specific accuracy evaluation, in addition to calculating the total area of classes, their location is also considered. In this project, the sites specific accuracy assessment method was used [29].

After drawing, the classification map (Figure 7) and reference map (Figure 3) were examined using ENVI software and the Confusion Matrix method in terms of location and the area of the formations. Use Confusion Matrix to show the accuracy of a classification result by comparing a classification result with ground truth information [30]. The Confusion Matrix report shows the overall accuracy, kappa coefficient, errors of commission (percentage of extra pixels in class), errors of omission (percentage of pixels left out of class), producer accuracy, and user accuracy for each class [24]. 


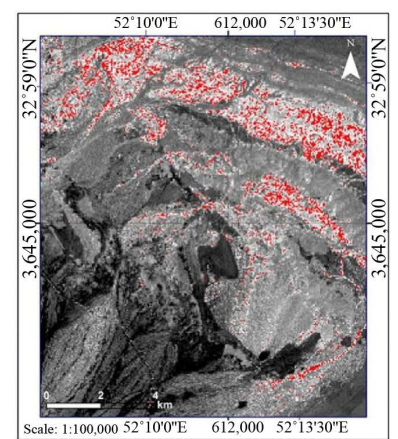

(a)

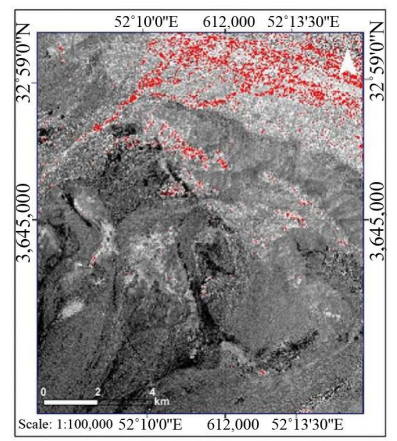

(e)

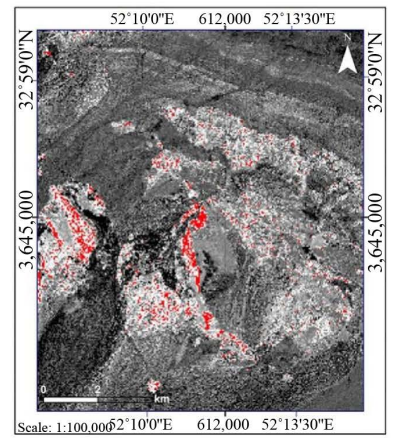

(i)

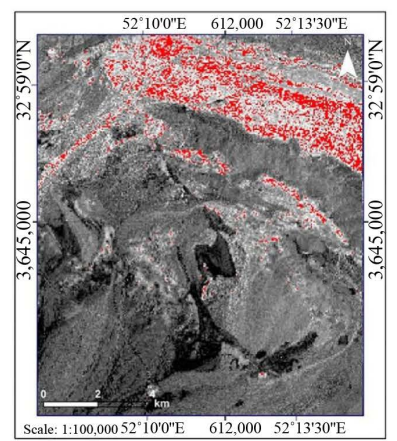

(m)

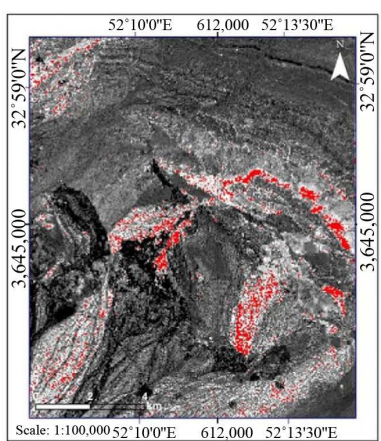

(b)

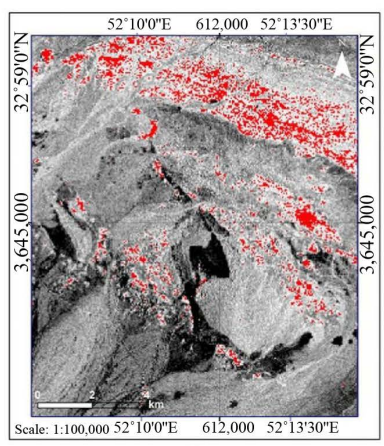

(f)

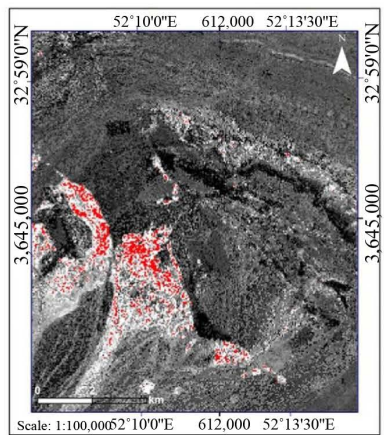

(j)

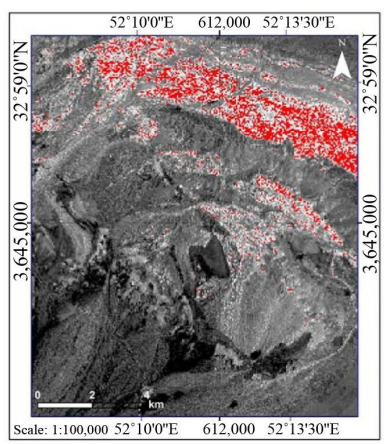

(n)

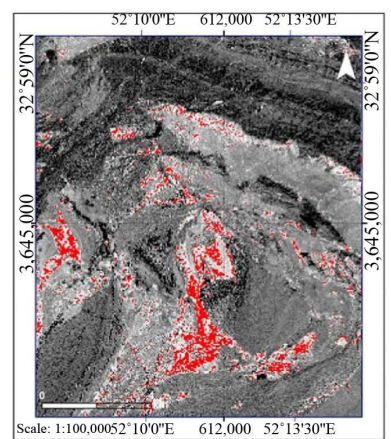

(c)

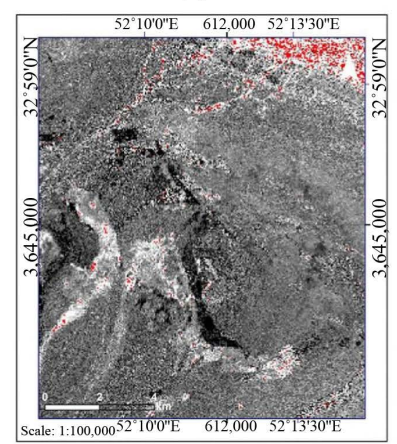

(g)

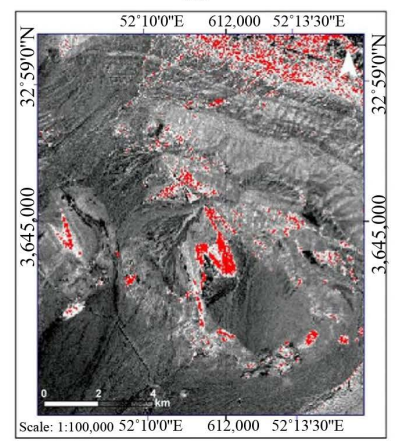

(k)

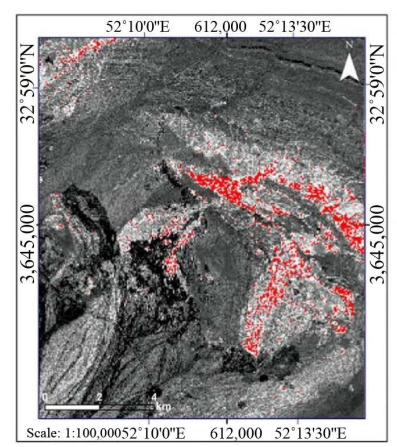

(o)

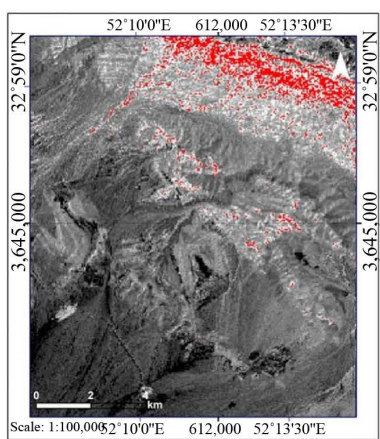

(d)

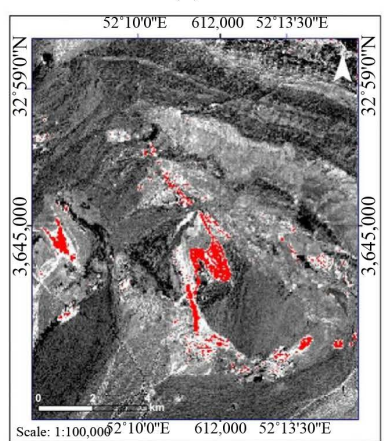

(h)

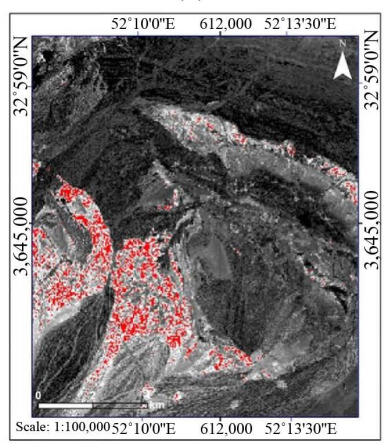

(1)

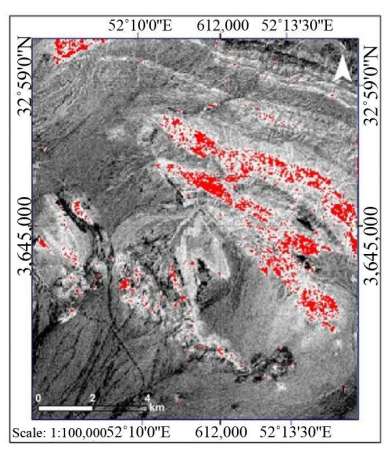

(p)

Figure 6. The images from Spectral Analogues method in OLI data.

The kappa coefficient $(K)$ "Equation (1)" is another measure of the accuracy of the classification. It is calculated by multiplying the total number of pixels in all the ground truth classes $(N)$ by the sum of the confusion matrix diagonals $\left(\sum_{i=1}^{k} n_{i i}\right)$, subtracting the sum of the ground truth pixels in a class times the 
sum of the classified pixels in that class summed over all classes $\left(\sum_{i=1}^{k} n_{i+} \times n_{+i}\right)$, and dividing by the total number of pixels squared minus the sum of the ground truth pixels in that class times the sum of the classified pixels in that class summed over all classes [24].

$$
K=\frac{N \sum_{i=1}^{k} n_{i i}-\sum_{i=1}^{k} n_{i+} \times n_{+i}}{N^{2}-\sum_{i=1}^{k} n_{i+} \times n_{+i}}
$$

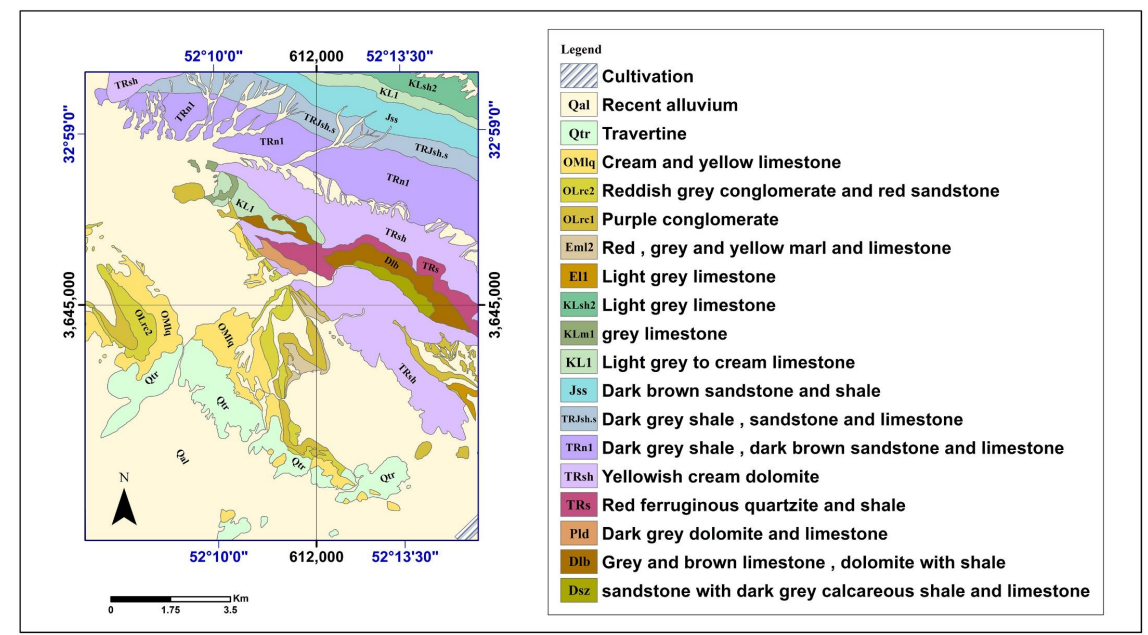

Figure 7. The map drawn from applying MF and Spectral Analogues methods.

Table 1. The properties of images from the MF method (for image name see Figure 5).

\begin{tabular}{|c|c|c|c|c|}
\hline Image name & Selected Train & Description & Detected formations & $\begin{array}{c}\text { Description } \\
\text { (Most often contain) }\end{array}$ \\
\hline$(5-a)$ & Dsz & $\begin{array}{l}\text { Sandstone and volcanoclastic beds with } \\
\text { dark grey calcareous shale and limestone }\end{array}$ & Dlb-Dsz-TRn1 TRJsh.s & $\begin{array}{l}\text { Limestone, shale } \\
\text { Detected Color: Grey }\end{array}$ \\
\hline$(5-b)$ & El1 & Light grey limestone & EL1-OMlq-Qtr & Calcareous compounds, Limestone \\
\hline$(5-c)$ & Jss & $\begin{array}{l}\text { Dark brown sandstone with } \\
\text { intercalation of shale }\end{array}$ & Jss-Kc1-Olrc2 TRn1 & $\begin{array}{c}\text { Sandstone } \\
\text { Detected Color: Red to brown }\end{array}$ \\
\hline$(5-d)$ & KLsh2 & $\begin{array}{l}\text { Light grey limestone, sandy limestone } \\
\text { and silty marl }\end{array}$ & OMlq-KLsh2-KL1 & Limestone, marl \\
\hline$(5-e)$ & OLrc1 & $\begin{array}{l}\text { Purple polymict conglomerate, Lower } \\
\text { Red Formation }\end{array}$ & OLrc1 & Purple conglomerate \\
\hline$(5-f)$ & OLrc2 & $\begin{array}{c}\text { Reddish grey conglomerate and red } \\
\text { sandstone with bentonite horizon, Lower } \\
\text { Red Formation }\end{array}$ & OLrc2 & Reddish grey conglomerate \\
\hline$(5-g)$ & OMlq & $\begin{array}{l}\text { Cream and yellow fossiliferous limestone, } \\
\text { marl and sandy marl, Qom Formation }\end{array}$ & OMlq & Limestone, marl \\
\hline$(5-h)$ & Qtr & Travertine & Qtr-OMlq & Calcareous compounds, Limestone \\
\hline$(5-i)$ & TRJsh.s & $\begin{array}{l}\text { Dark grey shale and sandstone, sandy } \\
\text { limestone }\end{array}$ & TRJsh.s-TRn1 & $\begin{array}{l}\text { Sandstone, grey limestone, shale } \\
\text { Detected Color: Grey }\end{array}$ \\
\hline$(5-j)$ & TRn1 & $\begin{array}{l}\text { Dark grey shale, dark brown sandstone } \\
\text { and intercalations of limestone and } \\
\text { dolomite, Nayband Formation }\end{array}$ & TRn1-Dlb-TRJsh.s Jss & $\begin{array}{l}\text { Sandstone, limestone, shale } \\
\text { Detected Color: Red to brown }\end{array}$ \\
\hline$(5-k)$ & TRs & $\begin{array}{l}\text { Red ferruginous quartzite and shale, } \\
\text { equivalent to Sorkh Shale Formation }\end{array}$ & TRs & Quartzite and shale \\
\hline$(5-1)$ & TRsh & $\begin{array}{l}\text { Yellowish cream dolomite Shotori } \\
\text { Formation }\end{array}$ & TRsh & Dolomite \\
\hline
\end{tabular}


Table 2. The properties of images from the Spectral Analogues method (for image name see Figure 6).

\begin{tabular}{|c|c|c|c|c|c|}
\hline Image name & $\begin{array}{l}\text { Selected } \\
\text { Train }\end{array}$ & Description & Output & Detected formations & $\begin{array}{c}\text { Description } \\
\text { (Most often contain) }\end{array}$ \\
\hline$(6-a)$ & $\mathrm{Dlb}$ & $\begin{array}{l}\text { The brown fossiliferous } \\
\text { limestone, dolomite and shale }\end{array}$ & MF/SAM & $\begin{array}{l}\text { Dlb-Dsz-TRn1 } \\
\text { TRJsh.s-KLm1 }\end{array}$ & limestone \\
\hline (6-b) & EL1 & Light grey limestone & MF/SAM & El1-TRs & Calcareous compounds \\
\hline$(6-c)$ & $\mathrm{Eml} 2$ & $\begin{array}{l}\text { Red, grey and yellow marl with } \\
\text { nummulitic limestone }\end{array}$ & MF/SAM & Eml2-OLrc1 & Limestone, Red marl \\
\hline$(6-d)$ & Jss & $\begin{array}{l}\text { Dark brown sandstone with } \\
\text { intercalation of shale }\end{array}$ & MF/SAM & Jss-KL1 & Shale \\
\hline$(6-e)$ & KL1 & $\begin{array}{l}\text { Light grey to cream limestone, } \\
\text { sandy limestone, marl and shale }\end{array}$ & MF/SAM & Jss-TRJsh.s-KLsh2 & Limestone, marl, shale \\
\hline$(6-f)$ & KLm1 & $\begin{array}{l}\text { Alternation of grey limestone } \\
\text { and greenish olive marl }\end{array}$ & MF & $\begin{array}{l}\text { Dlb-Dsz-TRn1 } \\
\text { TRJsh.s-KLm1 }\end{array}$ & $\begin{array}{l}\text { Limestone, shale } \\
\text { Detected Color: Grey }\end{array}$ \\
\hline$(6-g)$ & KLsh2 & $\begin{array}{l}\text { Light grey limestone, sandy } \\
\text { limestone and silty marl }\end{array}$ & $\mathrm{MF} / \mathrm{SAM}$ & KLsh2 & Limestone, marl \\
\hline$(6-h)$ & OLrc1 & $\begin{array}{l}\text { Purple polymict conglomerate, } \\
\text { Lower Red Formation }\end{array}$ & MF/SAM & OLrc1 & Purple conglomerate \\
\hline$(6-i)$ & OLrc2 & $\begin{array}{l}\text { Reddish grey conglomerate and } \\
\text { red sandstone with bentonite } \\
\text { horizon, Lower Red Formation }\end{array}$ & MF/SAM & OLrc2 & Reddish grey conglomerate \\
\hline$(6-j)$ & OMlq & $\begin{array}{c}\text { Cream and yellow fossiliferous } \\
\text { limestone, marl and sandy marl, } \\
\text { Qom Formation }\end{array}$ & MF/SAM & OMlq & Limestone, marl \\
\hline$(6-k)$ & Pld & $\begin{array}{l}\text { Dark grey dolomite and } \\
\text { fossiliferous limestone }\end{array}$ & $\mathrm{MF} / \mathrm{SAM}$ & Pld-Jss-KL1-OLrc1-KLsh2 & Grey Limestone \\
\hline$(6-1)$ & Qtr & Travertine & MF/SAM & OMlq-Qtr & Limestone, Travertine \\
\hline$(6-\mathrm{m})$ & TRJsh.s & $\begin{array}{l}\text { Dark grey shale and sandstone, } \\
\text { sandy limestone }\end{array}$ & MF/SAM & Dlb-TRn1-TRJsh.s-KL1-Jss & Grey Limestone, shale \\
\hline$(6-n)$ & TRn1 & $\begin{array}{l}\text { Dark grey shale, dark brown } \\
\text { sandstone and intercalations of } \\
\text { limestone and dolomite, } \\
\text { Nayband Formation }\end{array}$ & $\mathrm{MF} / \mathrm{SAM}$ & Dlb-TRn1-TRJsh.s-Kc1-Jss & Sandstone, grey limestone, shale \\
\hline$(6-0)$ & TRs & $\begin{array}{c}\text { Red ferruginous quartzite and } \\
\text { shale, equivalent to Sorkh Shale } \\
\text { Formation }\end{array}$ & $\mathrm{MF} / \mathrm{SAM}$ & TRs-El1 & Calcareous compounds \\
\hline$(6-p)$ & TRsh & $\begin{array}{l}\text { Yellowish cream dolomite } \\
\text { Shotori Formation }\end{array}$ & MF & TRsh & Dolomite \\
\hline
\end{tabular}

The overall accuracy is calculated by summing the number of pixels classified correctly and dividing by the total number of pixels "Equation (2)". The ground truth image or ground truth ROIs defines the true class of the pixels. The pixels classified correctly are found along the diagonal of the confusion matrix table which lists the number of pixels that were classified into the correct ground truth class. The total number of pixels is the sum of all the pixels in all the ground truth classes [24].

$$
O A=\frac{\sum_{i=1}^{k} n_{i i}}{N}
$$

In this regard ( $\left.\sum_{i=1}^{k} n_{i i}\right)$ is sum of diagonal elements and $(N)$ the total number of pixels [31]. 
The output error images are mask images, one for each class, where all correctly classified pixels have a value of 0 and incorrectly classified pixels have a value of 1 . The last error image band (Figure 8 ) shows all the incorrectly classified pixels for all the classes combined [24]. Using the Kappa index value, the accuracy rate for the selected formations is $86 \%$, so this map's accuracy is acceptable (Table 3).

\section{Conclusion}

In this research, the ASTER and OLI data were used.. The noise data value reduced significantly by applying the atmospheric, geometric and topographic corrections. The SWIR and VNIR bands were used in the ASTER and OLI data for features detection. For a better detection of the region's formations using the Region of Interest method the selected train was taken in both data, considering that each formation consisted of several sedimentary units and it was affected by recent sediments. These selected trains were used for OLI data and ASTER data in the

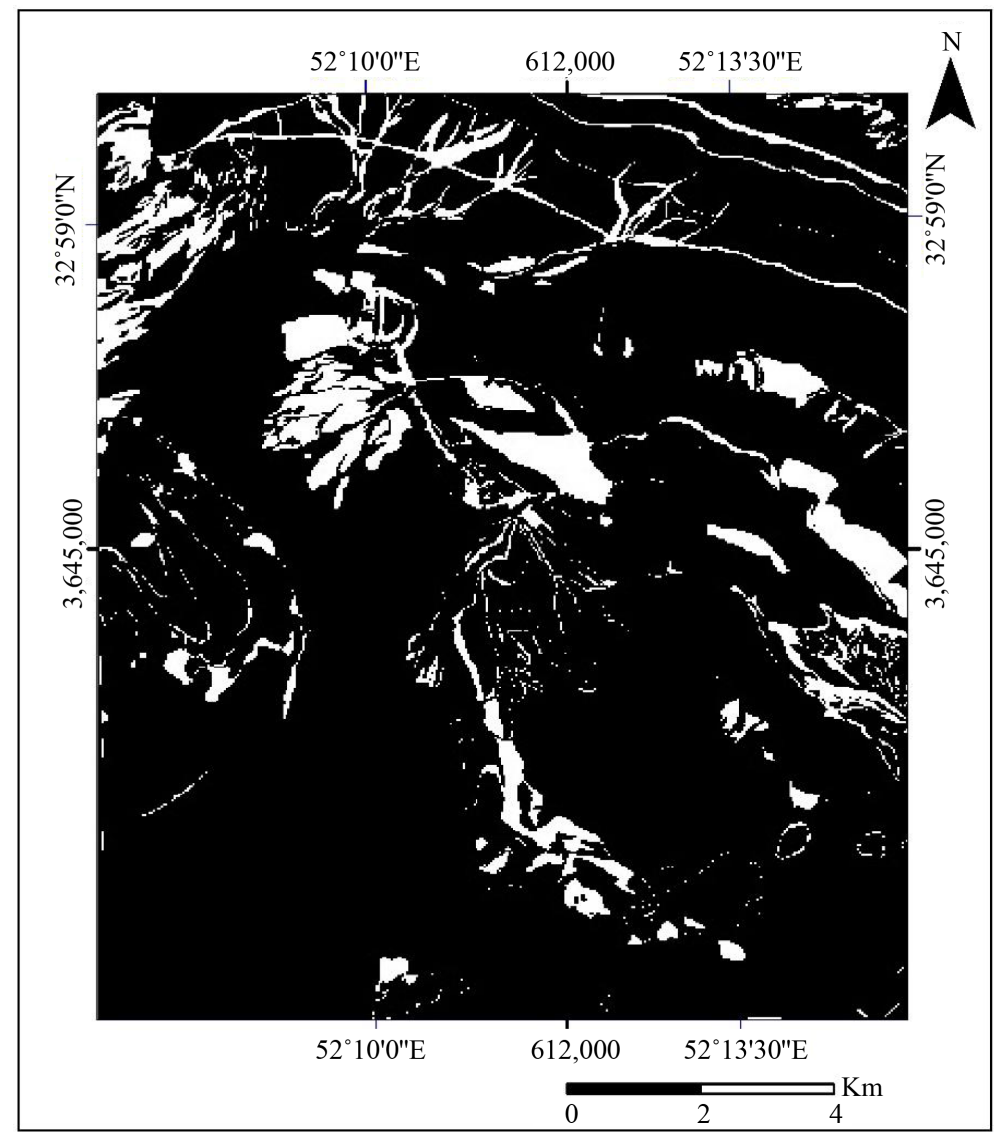

Figure 8. Image of Total Class Error.

Table 3. The accuracy of the prepared map.

\begin{tabular}{ccc}
\hline Overall Accuracy & Kappa index & Kappa index $\%$ \\
\hline 0.9 & 0.86 & $86 \%$ \\
\hline
\end{tabular}


Spectral Analogues and the MF method, respectively. At last, by comparing the formations obtained from these two methods and the RGB (652) band composite in OLI data, the formation's map of the region was drawn. In the Spectral Analogues method, the MF/SAM output images have the most adaptation to the region's formations according to examining the SAM, MF, MF/SAM output images. Due to higher radiometric resolution, OLI data is more efficient than ASTER data in detecting the region's formation. The thematic accuracy method was used for formation's map accuracy assessment. In terms of area and location, each formation in the drawn map was compared with the reference map and finally, the map accuracy $86 \%$ was confirmed.

\section{References}

[1] Rowan, L.C., Goetz, A.F.H. and Ashley, R.P. (1977) Discrimination of Hydrothermally Altered and Unaltered Rocks in Visible and Nearinfrared Multispectral Images. Geophysics, 42, 522-535. https://doi.org/10.1190/1.1440723

[2] Goetz, A.F.H., Rock, B.N. and Rowan, L.C. (1983) Remote Sensing for Exploration: An Overview. Economic Geology, 78, 573-590.

https://doi.org/10.2113/gsecongeo.78.4.573

[3] Boardman, J.W. and Kruse, F.A. (1994) Automated Spectral Analysis: A Geological Example Using AVIRIS Data, North Grapevine Mountains, Nevada. In: ERIM, Ed., Proc. 10th Thematic Conference on Geological Remote Sensing, San Antonio, 9-12 May 1994, 407-418.

[4] Papp, E. and Cudahy, T. (2002) Hyperspectral Remote Sensing. In: Papp, E., Ed., Geophysical and Remote Sensing Methods for Regolith Exploration. CRC LEME Open File Report, 144, 13-21.

[5] Kruse, F.A., Boardman, J.W. and Huntington, J.F. (2003) Comparison of Airborne Hyperspectral Data and EO-1 Hyperion for Mineral Mapping. IEEE Transactions on Geoscience and Remote Sensing, 41, 1388-1400. https://doi.org/10.1109/TGRS.2003.812908

[6] Perry, S.L. (2004) Spaceborne and Airborne Remote Sensing Systems for Mineral Exploration-Case Histories Using Infrared Spectroscopy. In: King, P.L., Ramsey, M.S. and Swayze, G.A., Eds., Infrared Spectroscopy in Geochemistry, Exploration Geochemistry, and Remote Sensing. Mineralogic Association of Canada, London, 227-240.

[7] Guo Liu, J. and Mason, P. (2009) Essential Image Processing and GIS for Remote Sensing. Wiley Press, 462. https://doi.org/10.1002/9781118687963

[8] Yamaguchi, Y., Kahle, A.B. and Kawakami, T. (1998) Overview of the Advanced Spaceborne Thermal Emission and Reflection Radiometer (ASTER). IEEE Transaction on Geoscience and Remote Sensing, 36, 1062-1071. https://doi.org/10.1109/36.700991

[9] Nair, A. and Mathew, G. (2012) Lithological Discrimination of the Phenaimata Felsic-Mafic Complex, Gujarat, India, Using the Advanced Spaceborne Thermal Emission and Reflection Radiometer (ASTER). International Journal of Remote Sensing, 33, 198-219. https://doi.org/10.1080/01431161.2011.591441

[10] Xiong, Y.Q., Khan, S.D. and Mahmood, K. (2011) Lithological Mapping of Bela Ophiolite with Remote-Sensing Data. International Journal of Remote Sensing, 32, 4641-4658. https://doi.org/10.1080/01431161.2010.489069

[11] Amer, R., Kusky, T. and Ghulam, A. (2010) Lithological Mapping in the Central 
Eastern Desert of Egypt using ASTER Data. Journal of African Earth Sciences, 56, 75-82.

[12] Ninomiya, Y., Fu, B.H. and Cudahy, T.J. (2005) Detecting Lithology with Advanced Spaceborne Thermal Emission and Reflection Radiometer (ASTER) Multispectral Thermal Infrared “Radiance-at-Sensor” Data. Remote Sensing of Environment, 99, 127-139.

[13] Rowan, L.C., Mars, J.C. and Simpson, C.J. (2005) Lithologic Mapping of the Mordor, NT, Australia Ultramafic Complex by Using the Advanced Spaceborne Thermal Emission and Reflection Radiometer (ASTER). Remote Sensing of Environment, 99, 105-126.

[14] USGS (2016) United States Geological Survey (Using ENVI). http://www.USGS.gov

[15] (2015) Landsat 8 Data Users Handbook V 1.0.

[16] Schwarz, C., Katzschmann, L. and Radzinski, K.H. (2002) Geological Mapping: General Basics. Schweizerbart'Sche Verlagsbuchhandlung Press, 135.

[17] Alavi, M. (1994) Tectonics of the Zagros Orogenic Belt of Iran: New Data and Interpretations. Tectonophysics, 229, 211-238.

[18] Aghanabati, A. (2004) Geology of Iran (Stratigraphy, Tectonics, Metamorphism, Magmatism). Amir Kabir Press, Tehran, 434.

[19] Hairapetian, V., Arfania, R. and Hejazi, H. (2015) Geological Report of the Pasab-e-Bala Map (1:25000): Geological Survey and Mineral Explorations Country.

[20] Kaufman, Y.J., Wald, A.E. and Remer, L.A. (1997) The MODIS 2.1- $\mu$ m Channel Correlation with Visible Reflectance for Use in Remote Sensing of Aerosol. IEEE Transactions on Geoscience and Remote Sensing, 35, 1286-1298. https://doi.org/10.1109/36.628795

[21] Ranjbar, H., Shahriari, H. and Honarmand, M. (2003) Comparison of ASTER and ETM+ Data for Exploration of Porphyry Copper Mineralization: A Case Study of Sarcheshmeh Area, Kerman, Iran. Map Asia Conference, Kuala Lumpur, 13-15 October 2003.

[22] Acharya, D.T. and Yang, I. (2015) Exploring Landsat 8. International Journal of IT, Engineering and Applied Sciences Research, 4, 4-10.

[23] Green, A.A., Berman, M., Switzer, P. and Craig, M.D. (1988) A Transformation for Ordering Multispectral Data in Terms of Image Quality with Implications for Noise Removal. IEEE Transactions on Geoscience and Remote Sensing, 26, 65-74. https://doi.org/10.1109/36.3001

[24] (2013) Envi Help V 5.3.

[25] Jensen, J.R. (2004) Introductory Digital Image Processing: A Remote Sensing Perspective. 3rd Edition, Prentice Hall, Upper Saddle River, 444-445.

[26] Khan, S.D., Mahmood, K. and Casey, J.F. (2007) Mapping of Muslim Bagh Ophiolite Complex (Pakistan) Using New Remote Sensing, and Field Data. Journal of Asian Earth Sciences, 30, 333-343.

[27] Turin, G.L. (1960) An Introduction to Matched Filters. IRE Transactions on Information Theory, 6, 311-329. https://doi.org/10.1109/TIT.1960.1057571

[28] (2013) Exelis Visual Information Solution.

[29] Russell, G. and Congalton, K.G. (2008) Assessing the Accuracy of Remotely Sensed Data: Principles and Practices. CRC Press, 200.

[30] Jensen, J.R. (1986) Introductory Digital Image Processing, Prentice-Hall, Englewood Cliffs, 379. 
[31] Yousefi, S., Tazeh, M., Mirzaee, S., Moradi, H. and Tavangar, S. (2014) Comparison of Different Classification Algorithms in Satellite Imagery to Produce Land Use Maps. Noor City, Case Study.

\section{Appendix}

\section{Abbreviation}

ASTER: Advanced Space borne Thermal Emission and Reflection Radiometer ENVI: Environment for Visualizing Images

ETM+: Enhanced Thematic Mapper Plus

FCC: False Color Composite

FLAASH: Fast Line-of-sight Atmospheric Analysis of Spectral Hypercubes $\mu \mathrm{m}$ : Micrometer

MF: Matched Filtering

MNF: Minimum Noise Fraction

MTMF: Mixture Tuned Matched Filtering

NASA: National Aeronautics and Space Administration. www.gsfc.nasa.gov

OLI: Operational Land Imager

RGB: Red Green Blue

ROI: Region of Interest

SAM: Spectral Angle Mapper

SNR: signal-to-noise ratio

SPOT: System Pour Observation de La Terre

SWIR: Short Wavelength Infrared

TIMS: Thermal Infrared Multispectral Scanner

TIR: Thermal Infrared

TIRS: Thermal Infrared Sensor

USGS: United States Geological Survey. www.usgs.gov

VNIR: Visible and Near Infrared 